\title{
Myxoglobulosis in the appendix
}

\author{
Cengiz Koçak', Akile Zengin², İbrahim Girgin³ ${ }^{3}$ Fatma Ferda Kartufann', Mehmet Hüseyin Metineren ${ }^{1}$
}

ABSTRACT Myxoglobulosis is a specific type of mucocele consisting of mucoid material. It is characterized by opaque, transparent globules that resemble "fish eggs" or "frogspawns". It is generally diagnosed incidentally during an appendectomy or an autopsy. In this paper, we aim to present the case of a 58-year-old male patient who was referred to our hospital because of abdominal pain and loss of appetite. The patient underwent an appendectomy. Opaque intraluminal globules were found in the appendectomy material. The globules resembled pearls and they were $2-3 \mathrm{~mm}$ in diameter. After histopathological examinations, the patient was diagnosed with myxoglobulosis accompanied with acute appendicitis. According to our research, this is the first case of myxoglobulosis in our country.

Keywords: Acute appendicitis, myxoglobulosis, appendectomy

Cite this paper as: Koçak C, Zengin A, Girgin I, Kartufan FF, Metineren MH. Myxoglobulosis in the appendix. Turk J Surg 2017; 33: 308-310.

'Department of Pathology, Dumlupinar University School of Medicine, Kütahya, Turkey

2Department of General Surgery, Dumlupınar University School of Medicine, Kütahya, Turkey

${ }^{3}$ Clinic of General Surgery, Gediz State Hospital, Kütahya, Turkey

${ }^{4}$ Clinic of Anesthesiology, Gediz State Hospital, Kütahya, Turkey

Address for Correspondence Akile Zengin e-mail:dr.akile.zengin@gmail.com

Received:23.12.2014

Accepted: 29.03.2015

Available Online Date: 14.07.2015

CCopyright 2017

by Turkish Surgical Association

\section{INTRODUCTION}

Myxoglobulosis or caviar appendix is a special type of mucocele. It is characterized by the presence of opaque globules. Globules are made up of mucoid material and they form clusters that resemble "fish eggs" or "frogspawns." The first case of myxoglobulosis was described by Latham in 1897, who found the condition in a postmortem examination, as reported in the manuscript of Probstein and Lassar (1). In 1914 , the term "myxoglobulosis" was used by von Hansemann, who analyzed opaque globules varying in diameter from 0.1 to $1.0 \mathrm{~cm}$ (2), and it was described as a variant of mucocele. The etiology and pathogenesis of myxoglobulosis are still uncertain. Probstein and Lassar (1) have reported that the probable etiological factors are bacteria and necrotic epithelial debris, which may cause nidus formation for the deposition of mucin. Lubin and Berle (2) have reported that the core of the globules represent a mass of mucin by the granulation tissue that originated from the appendiceal wall and then these globules are disintegrated by mechanical contractions. Li et al. (3) have reported that the globules occur as a formation of mucin by the granulation tissue capsule and then these globules are extruded into the lumen by mechanical forces.

In this case report, we present an extremely rare case of appendiceal myxoglobulosis. According to our studies, this case is the first report of myxoglobulosis in our country.

\section{CASE PRESENTATION}

The procedures of this case were performed in accordance with the Declaration of Helsinki. The patient was instructed and then informed consent was received. A 58-year-old male patient was referred to the Gediz State Hospital in July 2012 with complaints of nausea and abdominal pain in the right lower abdomen. His historical and anamnestic data were not unusual, but he had a history of smoking for 46 years and had been diagnosed with chronic obstructive pulmonary disease. Physical examination revealed that he had rebound tenderness. His blood cell count tests showed that the number of white blood cells had slightly increased. Based on these findings, the patient was diagnosed with acute appendicitis. After spinal anesthesia was performed, the patient underwent an appendectomy. During the operation, the appendix was enlarged and distended. Then, the appendix was removed and appendectomy material was sent to our pathology laboratory for histopathological examination.

Macroscopic examination results revealed that the appendectomy specimen was $7 \mathrm{~cm}$ in length and 1 $\mathrm{cm}$ in thickness. In the area that was cut, the appendiceal lumen was dilated and filled with numerous opaque, whitish pearl-like globules 2-3 $\mathrm{mm}$ in diameter (Figure 1). The accumulation of these globules resembled fish eggs (Figure 2). Biopsy samples were examined histopathologically. On microscopic examination of samples stained by hematoxylin and eosin (H\&E), the globules which consisted of eosinophilic laminations of mucin surrounding an amorphous granular core were observed. The diffusion of inflammatory infiltration consisting of polymorphonuclear leucocytes and mononuclear cells were observed in the entire layer of the appendiceal wall. Furthermore, hemorrhage was evidently observed in the wall. Globules were positively stained with Alcian Blue (Figure 3, 4). Considering all these histo- 

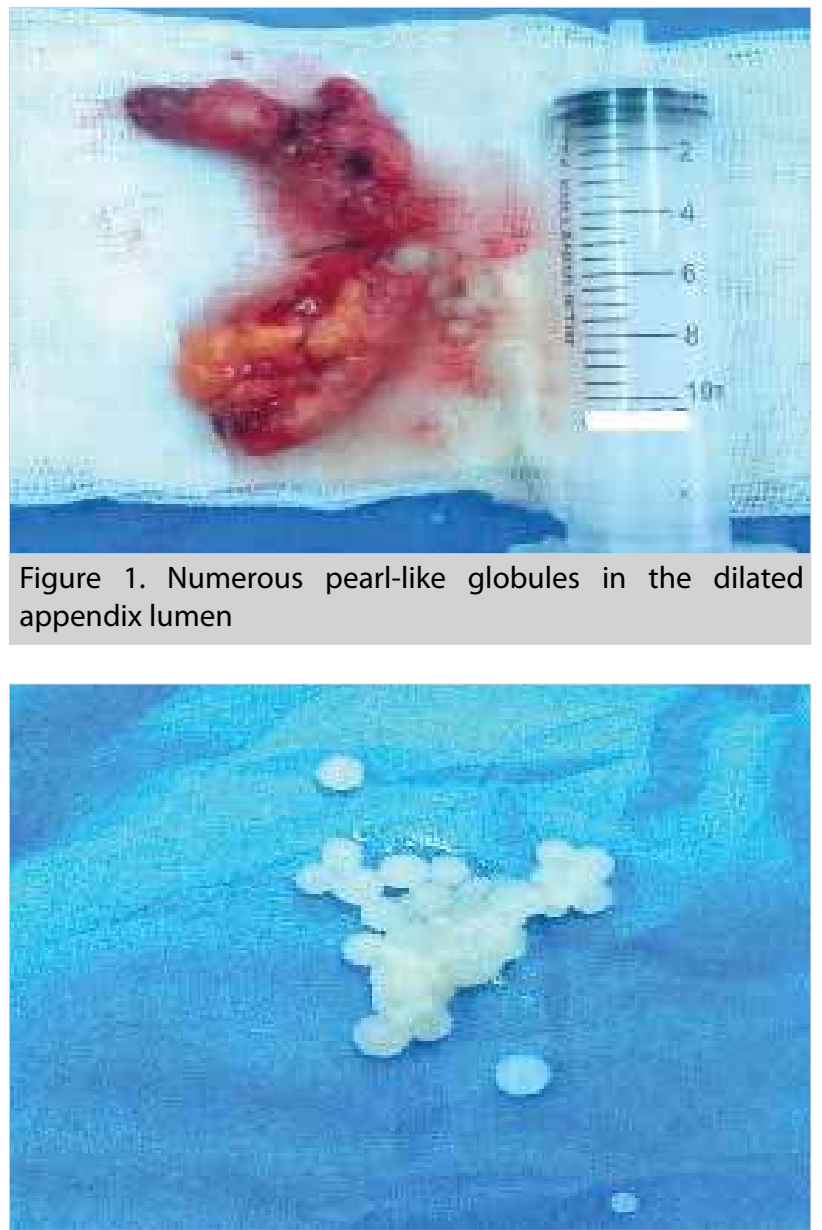

Figure 2. Macroscopic appearance of the globules resembling "fish eggs"

pathological findings, our case was diagnosed as myxoglobulosis accompanied with acute appendicitis.

\section{DISCUSSION}

The incidence of the appendiceal mucocele is estimated to be $0.2 \%-0.3 \%$ of the appendectomy specimens, with myxoglobulosis constituting $0.35 \%-0.8 \%$ of mucoceles (4-6). There are patients with myxoglobulosis who clinically exist in a manner similar to those with a mucocele of the appendix. The disorder occurs most commonly in the sixth or seventh decade of life. Patients are generally asymptomatic, and myxoglobulosis is found by chance during autopsies or laparotomies for other reasons. Sometimes, right lower abdominal pain and acute appendicitis is observed in patients with myxoglobulosis (7). To our knowledge, this case is the first report of myxoglobulosis in our country. The development of myxoglobulosis requires obstruction to the proximal appendiceal lumen with continued production of mucin distally. The causes of the proximal appendiceal obstruction include fecalith, epithelial hyperplasia, post-inflammatory fibrosis, cystadenoma, cystadenocarcinoma, carcinoid, and endometriosis. The characteristic feature is the presence of opaque, pearl-like globules in the appendiceal lumen. The most frequent complication is peritonitis or pseudomyxoma peritonei $(8,9)$. In the literature, the number of reported cases of myxoglobulosis is extremely rare. Recently, Aroukatos et al. (10) reported that a case of myxoglobulosis of the appendix is associated with a ruptured diverticulum. Falah et al. (11) have reported a case of appendiceal myxoglobulosis associated with peritonitis due to

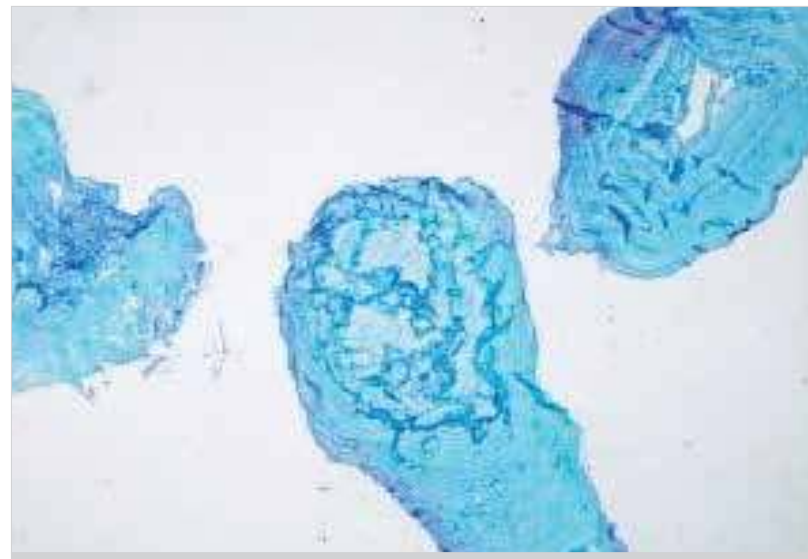

Figure 3. Alcian Blue positive staining of the globules (Alcian Blue $\mathrm{pH} 2.5 \times 20$ )

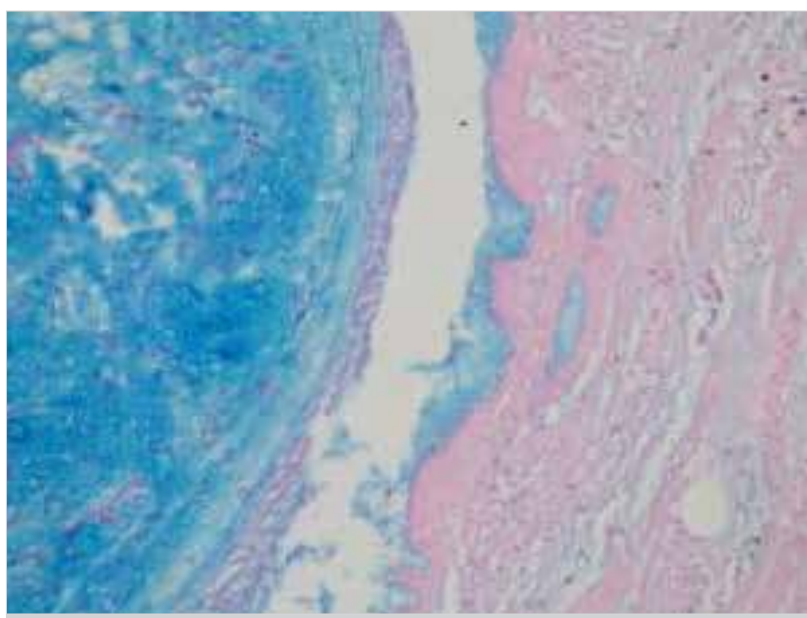

Figure 4. Alcian Blue positive staining of the globules and adjacent appendiceal luminal mucosa (Alcian Blue pH $2.5 \times 40$ )

perforated peptic ulcer. Padhy et al. (12) have reported a case of myxoglobulosis of the appendix. Routine histopathological examination is essential to diagnose myxoglobulosis.

\section{CONCLUSION}

In this paper, we have reported a rare case of myxoglobulosis, which was incidentally found in a patient with peritonitis due to acute appendicitis.

Informed Consent: Written informed consent was obtained from patient who participated in this case.

Peer-review: Externally peer-reviewed.

Author Contributions: Concept - C.K., I.G., F.F.K.; Design - A.Z., M.H.M.; Supervision - I.G.; Funding - A.Z.; Materials - M.H.M.; Data Collection and/or Processing - I.G.; Analysis and/or Interpretation - M.H.M.; Literature Review - C.K., A.Z., F.F.K.; Writer - A.Z.; Critical Review - C.K., F.F.K.

Conflict of Interest: No conflict of interest was declared by the authors.

Financial Disclosure: The authors declared that this study has received no financial support.

\section{REFERENCES}

1. Probstein JG, Lassar GN. Mucocele of the appendix, with myxoglobulosis. Ann Surg 1948; 127: 171-176. [CrossRef] 
Koçak et al.

Myxoglobulosis in the appendix

2. Lubin J, Berle E. Myxoglobulosis of the appendix. Report of two cases. Arch Pathol 1972; 94: 533-536.

3. Li TJ, Kitano M, Yoshida A, Iwashige Y, Yamashita S. Myxoglobulosis is an extravasation mucocele of the lower lip. J Oral Pathol Med 1997; 26: 342-344. [CrossRef]

4. Gonzalez JE, Hann SE, Trujillo YP. Myxoglobulosis of the appendix. Am J Surg Pathol 1988; 12: 962-966. [CrossRef]

5. Raijman I, Leong S, Hassaram S, Marcon NE. Appendiceal mucocele: endoscopic appearance. Endoscopy 1994; 26: 326-328. [CrossRef]

6. Madwed D, Mindelzun R, Jeffrey RB Jr. Mucocele of the appendix: imaging findings. AJR Am J Roentgenol 1992; 159: 69-72. [CrossRef]

7. Viswanath YK, Griffiths CD, Shipsey D, Oriolowo A, Johnson SJ. Myxoglobulosis, a rare variant of the appendiceal mucocele, occurring secondary to an occlusive membrane. J R Coll Surg Edinb 1998; 43: 204-206.
8. Brustmann H. Myxoglobulosis of the appendix associated with a proximal carcinoid and a pseudodiverticulum. Ann Diagn Pathol 2006; 10: 166-168. [CrossRef]

9. Alcalay J, Alkalay L, Lorent $\mathrm{T}$. Myxoglobulosis of the appendix. $\mathrm{Br} \mathrm{J}$ Radiol 1985; 58: 183-184. [CrossRef]

10. Aroukatos P, Verras D, Vandoros GP, Repanti M. Myxoglobulosis of the appendix: a case associated with ruptured diverticulum. Case Rep Med 2010; 2010: 745021. [CrossRef]

11. Falah HH, Maafi AA, Chatrnour G, Jahromi SK, Ebrahimi H. Myxoglobulosis, a rare variant of appendiceal mucocele : case report and review of the literature. Thrita J Med Sci 2013; 2: 155-158.

12. Padhy BP, Panda SK. Myxoglobulosis of appendix a rare entity. Indian J Surg 2013; 75: 337-339. [CrossRef] 